\title{
Synergetic effect of dilute acid and alkali treatments on fractional application of rice straw
}

\author{
Shaolong Sun, Weijing Chen, Jianing Tang, Bing Wang, Xuefei Cao, Shaoni Sun ${ }^{*}$ and Run-Cang Sun*
}

\begin{abstract}
Background: The biorefinery based on an effective and economical process is to fractionate the three primary constituents (cellulose, hemicelluloses, and lignin) from lignocellulosic biomass, in which the constituents can be respectively converted into high-value-added products. In this study, a successive treatment with dilute acid (0.25$1.0 \%$ aqueous $\mathrm{H}_{2} \mathrm{SO}_{4}, 100-150^{\circ} \mathrm{C}, 0.5-3.0 \mathrm{~h}$ ) and alkali $\left(1.5 \%\right.$ aqueous $\mathrm{NaOH}, 80^{\circ} \mathrm{C}, 3 \mathrm{~h}$ ) was performed to produce xylooligosaccharides (XOS), high-purity lignin, and cellulose-rich substrates to produce glucose for ethanol production from rice straw (RS).

Results: During the dilute acid pretreatment, the maximum production of XOS ( $12.8 \mathrm{~g} \mathrm{XOS} / 100 \mathrm{~g} \mathrm{RS})$ with a relatively low level of byproducts was achieved at a relatively low temperature $\left(130{ }^{\circ} \mathrm{C}\right)$ and a low $\mathrm{H}_{2} \mathrm{SO}_{4}$ concentration $(0.5 \%)$ for a reaction time of $2.0 \mathrm{~h}$. During the alkali post-treatment, $14.2 \mathrm{~g}$ lignin with a higher purity of $99.2 \%$ and $30.3 \mathrm{~g}$ glucose with a higher conversion rate by enzymatic hydrolysis were obtained from the successively treated substrates with $100 \mathrm{~g} \mathrm{RS}$ as starting material. As the pretreatment temperature, $\mathrm{H}_{2} \mathrm{SO}_{4}$ concentration, or time increased, more $\beta-O-4$ linkages in lignins were cleaved, which resulted in an increase of phenolic $\mathrm{OH}$ groups in lignin macromolecules. The signal intensities of $\mathrm{G}_{2}$ and $\mathrm{G}_{6}$ in $\mathrm{HSQC}$ spectra gradually reduced and vanished, indicating that a condensation reaction probably occurred at C-2 and C- 6 of guaiacyl with the side chains of other lignin.

Conclusions: The present study demonstrated that the successive treatments with dilute acid and alkali had a synergetic effect on the fractionation of the three main constituents in RS. It is believed that the results obtained will enhance the availability of the combined techniques in the lignocellulosic biorefinery for the application of the main components, cellulose, hemicelluloses, and lignin as biochemical and biofuels.
\end{abstract}

Keywords: Rice straw, Dilute acid pretreatment, Alkali treatment, Value-added application

\section{Background}

A significant type of biomass burning is a common way to eliminate waste after harvesting in China, such as in Shandong and Hebei Provinces, which is an important source of greenhouse gases and particulate pollutants in the atmosphere and has a remarkable effect on global atmospheric chemistry and global warming $[1,2]$. To avoid this pollution, many new schemes, including papermaking and bioethanol production are developed for the application of straw [3, 4]. These schemes mainly

*Correspondence: sunshaoni@126.com; rcsun3@bjfu.edu.cn Beijing Key Laboratory of Lignocellulosic Chemistry, Beijing Forestry University, Beijing 100083, China focus on the value-added application of cellulose. Note that rice straw consists of three major biomacromolecules, namely cellulose, hemicelluloses, and lignin, and each of these components has a distinct and complex structure $[5,6]$. Thus, rice straw can be considered as a potential renewable source of energy and biobased chemicals for economic development and environmental sustainability [7]. Unfortunately, although cellulose has been extensively applied in many fields, such as paper, food, and plastics industries as the predominant component of biomass, other components have not been fully utilized, particularly lignin $[8,9]$. 
The ultimate goal of rice straw separation according to the biorefinery is to obtain the fractionation of the three primary constituents via an effective and economical process, in which the three fractions can be converted into multiple biobased products, respectively. To date, a series of biorefinery processes for biomass including dilute acid, alkali, and steam explosion treatments have been investigated [10-12]. Among them, dilute acid pretreatment causes structural changes of lignin and cellulose as well as degradation of hemicelluloses, which in turn contribute to the reduction of biomass recalcitrance [13]. Simultaneously, xylooligosaccharides (XOS) were produced from hemicelluloses in biomass during the dilute acid pretreatment. More importantly, the pretreatment accelerates the subsequent delignification [5]. As a biorefinery process, there is a growing interest in lignin, the third most abundant component in biomass, for developing biobased materials and chemicals. In a typical cellulosic biomass, lignin fills the spaces between cellulose and hemicelluloses, holding the biomass matrix together [14]. Hence, it is necessary to isolate lignin from the pretreated biomass and to understand the structural features, which determine the final utilization of lignin. For example, lignin can be used as a substite for phenol in producing phenol-formaldehyde resins [15]. Interestingly, alkali treatment is a very effective method to separate lignin, especially from the pretreated biomass. It can further disrupt the cell wall by partially dissolving lignin and then obtain cellulose-rich residues [16]. Celluloserich residues can be further converted to glucose with high yields by enzymatic hydrolysis, which provides a high efficient way for bioethanol production.

As far as we know, although both acid and alkali pretreatments for the enzymatic hydrolysis of biomass have been intensively studied [17-20], very little concern is given to the fractional applications of the main components, cellulose, hemicelluloses, and lignin as biochemical and biofuels, especially during a combined treatment based on successive dilute acid and alkali treatments. For instance, in order to achieve high enzymatic hydrolysis efficiency, corncob was successively pretreated with acid and alkali to remove the non-cellulosic components [17]. Similarly, Kim et al. [18] reported the effects of sequential acid/alkali pretreatment on the enzymatic digestibility enhancement of empty palm fruit bunch fiber. For rice straw, sole dilute sulfuric acid or sole dilute alkali or combinations of them (dilute sulfuric acid and aqueous ammonia) have been studied [21-23]. However, these studies only focus on improving the enzymatic hydrolysis efficiency of the pretreated biomass. The recovery of hemicelluloses and lignin has not been investigated. Additionally, in almost all the cellulosic ethanol technologies, in pre-commercial stage, most of the hemicelluloses are preserved during pretreatment and then fermented into ethanol, while the structure and further utilization of the residual lignin are rarely reported.

In this study, a combination of successive dilute acid (0.25-1.0\% aqueous $\mathrm{H}_{2} \mathrm{SO}_{4}, 100-150{ }^{\circ} \mathrm{C}, 0.5-3.0 \mathrm{~h}$ ) and alkali $\left(1.5 \%\right.$ aqueous $\left.\mathrm{NaOH}, 80{ }^{\circ} \mathrm{C}, 3 \mathrm{~h}\right)$ treatments was proposed to enhance availability for the application of three major components (cellulose, hemicelluloses, and lignin) as biochemical and biofuels (XOS, high-purity lignin, and cellulose-rich substrates to produce glucose for ethanol production). The composition of XOS was determined by a high-performance anion-exchange chromatography (HPAEC). The yield, purity, molecular weight, and structural transformation of alkaline lignin isolated have been thoroughly investigated. Meanwhile, the cellulose-rich substrates were characterized by chemical constituent, scanning electron microscopy (SEM), Fourier transform infrared (FT-IR), and X-ray diffraction (XRD), and the yield of glucose was also determined. These results will provide useful information in the utilization of rice straw for the value-added biochemicals or bioethanol in biorefinery industry.

\section{Results and discussion}

Effects of successive dilute acid and alkali treatments on the chemical constituent, surface morphology, and crystallinity of the substrate

A biorefinery with successive dilute acid and alkali treatments was applied to enhance the value-added application of RS in this study. The scheme of the biorefinery process is shown in Fig. 1, and the corresponding solid yields obtained at various pretreating conditions are shown in Table 1. As shown, the solid yields decreased from 76.54 to $56.15 / 100 \mathrm{~g}$ RS as the pretreatment temperature, $\mathrm{H}_{2} \mathrm{SO}_{4}$ concentration, or time increased. This is mainly due to the degradation of hemicelluloses, which was further confirmed by the chemical constituents and FT-IR spectral analysis of the dilute acid pretreated substrates (Table 2; Additional file 1: Figure S1). During the dilute acid pretreatment, the hydronium ions released by the acid resulted in depolymerization of hemicelluloses by selective hydrolysis of glycosidic linkages, liberating $O$-acetyl group and other acid moieties to form acetic and uronic acids. These acids released are thought to catalyze the hydrolysis of hemicelluloses and oligosaccharides. For control substrate (control-S, without dilute acid pretreatment), the characteristic bands of acetyl ester units of hemicelluloses at $1728(\mathrm{C}=\mathrm{O}$ conjugates $)$ and $1246 \mathrm{~cm}^{-1}(\mathrm{C}-\mathrm{O})$ were observed by FT-IR spectra. As elevating severity, the intensities of the two bands were gradually reduced due to the deacetylation of hemicelluloses during the pretreatment [24]. When the pretreatment temperature was higher than $130{ }^{\circ} \mathrm{C}$ under the acid 




Fig. 1 Schematic illustration of the combined biorefinery processes

Table 1 The conditions of dilute acid pretreatment of rice straw and the solid yields obtained

\begin{tabular}{lllll}
\hline Entry & Temperature $\left({ }^{\circ} \mathbf{C}\right)$ & Time $(\mathbf{h})$ & $\mathbf{H}_{\mathbf{2}} \mathbf{S O}_{\mathbf{4}}(\%)$ & Solid yield (\%) \\
\hline 1 & 100 & 2 & 0.5 & 76.54 \\
2 & 110 & 2 & 0.5 & 72.01 \\
3 & 120 & 2 & 0.5 & 68.06 \\
$4,10,14$ & 130 & 2 & 0.5 & 64.65 \\
5 & 140 & 2 & 0.5 & 63.58 \\
6 & 150 & 2 & 0.5 & 61.62 \\
7 & 130 & 0.5 & 0.5 & 65.16 \\
8 & 130 & 1.0 & 0.5 & 65.12 \\
9 & 130 & 1.5 & 0.5 & 64.69 \\
11 & 130 & 2.5 & 0.5 & 62.68 \\
12 & 130 & 3.0 & 0.5 & 60.10 \\
13 & 130 & 2.0 & 0.25 & 66.91 \\
15 & 130 & 2.0 & 0.6 & 62.28 \\
16 & 130 & 2.0 & 0.7 & 61.73 \\
17 & 130 & 2.0 & 0.8 & 59.91 \\
18 & 130 & 2.0 & 1.0 & 56.15 \\
\hline
\end{tabular}

conditions, the two bands almost disappeared, confirming the significant degradation of hemicelluloses. During the dilute acid pretreatment, most of hemicelluloses were degraded, while lignin was retained in the pretreated substrates. In fact, most lignin embeds in the spaces of the plant cell walls and enhances the mechanical strength of the cell walls through covalently linked hemicelluloses. Previous literature reported that lignin had negative effects on the access of enzymes to cellulose [25]. In order to improve the glucose yield of biomass, an appropriate pretreatment should be employed to remove lignin from the pretreated substrates. Alkali solutions, such as aqueous $\mathrm{NaOH}$, are widely used to disrupt the rigid structure of the cell wall for the separation of the main components of biomass. Wen et al. [26] demonstrated the yield, purity, dissociation mechanisms, and structural features of dissolved lignin (DL), milled wood lignin (MWL), and alkali lignin (AL) of the bamboo, and their results showed that the yield of AL was significantly higher than those of DL and MWL. In addition, Xiao et al. [27] also pointed out that solution of $1 \% \mathrm{NaOH}$ at $75{ }^{\circ} \mathrm{C}$ for $3 \mathrm{~h}$ was an effective method to disrupt the recalcitrant nature of the plant cell wall. Therefore, based on the above investigations, a further treatment was performed with $1.5 \%$ aqueous $\mathrm{NaOH}$ at $80{ }^{\circ} \mathrm{C}$ for $3 \mathrm{~h}$ to isolate lignin from the pretreated substrates. As shown in Table 2, the contents of hemicelluloses and lignins unceasingly decreased in the post-treated substrates as compared to the pretreated substrates alone, further verifying that the delignification with alkali treatment effectively removed lignins and the residual hemicelluloses from the pretreated substrates. Especially, after the post-treatment process, the removal of lignins can enhance the glucose yield of substrate. Meanwhile, the lignins obtained as byproducts can also be recovered for further utilization. Furthermore, the disappearance of the two bands at 1728 and $1246 \mathrm{~cm}^{-1}$ in the post-treated substrates revealed that alkali treatment completely cleaved the ester bands of hemicelluloses, such as acetyl and uronic ester groups [28].

The morphological changes of the pretreated and post-treated substrates were measured by SEM images (Additional file 1: Figure S2). The control-S exhibited a smooth and rigid surface structure. By contrast, the surfaces of the pretreated substrates were broken into separated fibers or fiber bundles and appeared cracks on different levels. The reason for this was mainly that the degradation of hemicelluloses during the pretreatment opened up macropores. During the further alkali treatment, the surface morphology of the substrates became looser with wider separation of the fibers than the pretreated substrates alone. This was possible that most of lignins and residual hemicelluloses were removed during the alkali post-treatment. The removal of both hemicelluloses and lignins resulted in the release of a larger specific surface area, which favored the following enzymatic hydrolysis. 
Table 2 Chemical compositions of the control, pretreated, and post-treated substrates under various conditions

\begin{tabular}{|c|c|c|c|c|c|c|c|}
\hline & \multicolumn{3}{|c|}{ Chemical composition (w/w, \%) } & & \multicolumn{3}{|c|}{ Chemical composition (w/w, \%) } \\
\hline & $\mathrm{Hemi}^{\mathbf{b}}$ & Cellulose & Lignin & & $\mathrm{Hemi}^{\mathbf{b}}$ & Cellulose & Lignin \\
\hline Control-S & 27.46 & 38.29 & 20.50 & Control-R & 33.57 & 56.45 & 3.00 \\
\hline$S_{(100-0.5-2)}$ & 14.95 & 48.22 & 26.90 & $R_{(100-0.5-2)}$ & 13.03 & 78.37 & 2.53 \\
\hline$S_{(110-0.5-2)}$ & 12.61 & 50.25 & 28.40 & $R_{(110-0.5-2)}$ & 7.13 & 80.29 & 2.81 \\
\hline$S_{(120-0.5-2)}$ & 7.56 & 51.86 & 30.63 & $R_{(120-0.5-2)}$ & 4.17 & 81.93 & 6.38 \\
\hline $\mathrm{S}_{(130-0.5-2)}$ & 5.18 & 53.51 & 31.47 & $\mathrm{R}_{(130-0.5-2)}$ & 3.14 & 82.29 & 7.23 \\
\hline$S_{(140-0.5-2)}$ & 4.39 & 55.04 & 31.93 & $R_{(140-0.5-2)}$ & 2.26 & 82.81 & 7.89 \\
\hline $\mathrm{S}_{(150-0.5-2)}$ & 2.36 & 57.16 & 32.80 & $\mathrm{R}_{(150-0.5-2)}$ & 1.03 & 84.29 & 8.31 \\
\hline$S_{(130-0.5-0.5)}$ & 8.08 & 51.84 & 30.33 & $R_{(130-0.5-0.5)}$ & 5.32 & 79.34 & 5.30 \\
\hline$S_{(130-0.5-1)}$ & 6.96 & 52.10 & 31.33 & $\mathrm{R}_{(130-0.5-1)}$ & 3.83 & 80.15 & 5.56 \\
\hline$S_{(130-0.5-1.5)}$ & 5.91 & 52.79 & 31.32 & $\mathrm{R}_{(130-0.5-1.5)}$ & 2.53 & 81.82 & 5.88 \\
\hline$S_{(130-0.5-2.5)}$ & 4.09 & 55.02 & 32.73 & $R_{(130-0.5-2.5)}$ & 2.33 & 82.29 & 6.75 \\
\hline$S_{(130-0.5-3)}$ & 3.49 & 57.14 & 33.13 & $\mathrm{R}_{(130-0.5-3)}$ & 1.84 & 83.81 & 7.61 \\
\hline$S_{(130-0.25-2)}$ & 8.51 & 52.71 & 29.87 & $R_{(130-0.25-2)}$ & 4.47 & 80.17 & 5.42 \\
\hline$S_{(130-0.6-2)}$ & 5.15 & 54.51 & 31.93 & $\mathrm{R}_{(130-0.6-2)}$ & 1.95 & 83.01 & 7.00 \\
\hline$S_{(130-0.7-2)}$ & 3.44 & 59.04 & 32.30 & $R_{(130-0.7-2)}$ & 1.80 & 84.55 & 8.58 \\
\hline$S_{(130-0.8-2)}$ & 2.93 & 56.82 & 33.50 & $R_{(130-0.8-2)}$ & 1.47 & 82.23 & 9.60 \\
\hline$S_{(130-1-2)}$ & 1.87 & 29.08 & 59.61 & $R_{(130-1-2)}$ & 1.17 & 78.13 & 11.43 \\
\hline
\end{tabular}

Crystallinity is an essential factor that reflects the hydrolysis properties of substrates. The crystalline region hinders cellulases accessing to the cell walls of fibers, resulting in the reduction of cellulose hydrolysis [29]. The crystallinity indexes (CrIs) of the pretreated and posttreated substrates were determined by XRD patterns (Additional file 1: Figure S3) and the results are listed in Table 3. As compared to the CrI of control-S (34.0\%), the CrIs of the pretreated substrates increased from 40.8 to $43.0 \%$ with the increase of the pretreatment temperature, $\mathrm{H}_{2} \mathrm{SO}_{4}$ concentration, or time. This increasing trend was

Table 3 The crystallinity indexes of the control, pretreated, and the cellulose-rich fractions obtained by the integrated treatment

\begin{tabular}{llll}
\hline & Crl (\%) & & Crl (\%) \\
\hline Control-S & 34.0 & Control-R & 42.1 \\
$\mathrm{~S}_{(100-0.5-2)}$ & 40.8 & $\mathrm{R}_{(100-0.5-2)}$ & 42.8 \\
$\mathrm{~S}_{(130-0.5-2)}$ & 43.0 & $\mathrm{R}_{(130-0.5-2)}$ & 48.9 \\
$\mathrm{~S}_{(150-0.5-2)}$ & 41.7 & $\mathrm{R}_{(150-0.5-2)}$ & 49.2 \\
$\mathrm{~S}_{(130-0.5-0.5)}$ & 40.3 & $\mathrm{R}_{(130-0.5-0.5)}$ & 47.6 \\
$\mathrm{~S}_{(130-0.5-3)}$ & 41.2 & $\mathrm{R}_{(130-0.5-3)}$ & 46.7 \\
$\mathrm{~S}_{(130-0.25-2)}$ & 42.8 & $\mathrm{R}_{(130-0.25-2)}$ & 44.8 \\
$\mathrm{~S}_{(130-1-2)}$ & 42.5 & $\mathrm{R}_{(130-1-2)}$ & 46.6 \\
\hline
\end{tabular}

attributed to the raise of cellulose concentration in the pretreated substrates due to the degradation and removal of amorphous hemicelluloses during the pretreatment process. However, the CrIs of the pretreated substrates began to decrease under a harsh condition $\left(130^{\circ} \mathrm{C}, 1.0 \%\right.$ $\mathrm{H}_{2} \mathrm{SO}_{4}, 2.0 \mathrm{~h}$ ), which was probably related to the partial degradation of crystalline cellulose. As expected, the further alkali treatment resulted in higher CrI values in the post-treated substrates, which was ascribed to the removal of lignins during the alkali post-treatment. Bi et al. [30] also reported that sodium hydroxide treatment enhanced the CrI of sugarcane bagasse since partial amorphous constituents (hemicelluloses and lignins) were removed during the treatment process.

\section{Effects of dilute acid pretreatments on xylooligosaccharides and degraded byproducts of polysaccharides}

The XOS production was influenced by the pretreatment conditions (Fig. 2). As the pretreatment temperature increased from 100 to $130{ }^{\circ} \mathrm{C}$, the yields of XOS were raised from 7.8 to $12.8 \mathrm{~g}$ XOS/100 g RS. However, when the pretreatment temperature further increased to $150{ }^{\circ} \mathrm{C}$, the yields of XOS rapidly declined (12.8-3.6 g $\mathrm{XOS} / 100 \mathrm{~g} \mathrm{RS})$. These phenomena were probably that the XOS were further degraded into other small molecules 


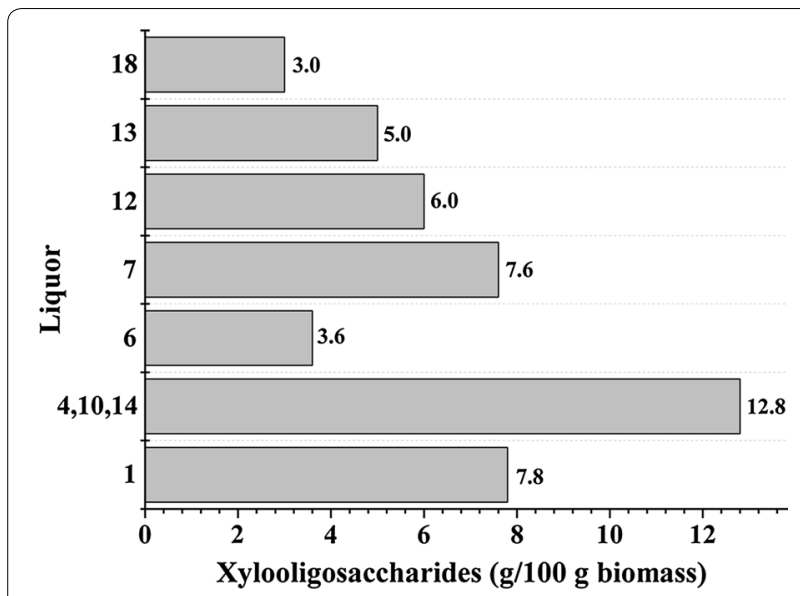

Fig. 2 The yield of xylooligosaccharides in the liquor phase obtained during the various dilute acid pretreatments. The liquid number ( 1 , $4,10,14,6,7$, etc.) on the y axis correspond to the liquids obtained during the dilute acid pretreatment of rice straw under various conditions, and pretreatment conditions are given in detail in Table 1

(such as furfural) under the harsh conditions, as revealed by the subsequent degraded byproducts analysis in the liquors produced during the pretreatment. Likewise, when the reaction time was prolonged from 0.5 to $2.0 \mathrm{~h}$ at $130{ }^{\circ} \mathrm{C}$ with $0.5 \% \mathrm{H}_{2} \mathrm{SO}_{4}$, the yield of XOS increased. However, further prolonging the reaction time to $3.0 \mathrm{~h}$, the yield of XOS rapidly reduced. Interestingly, the effect of dilute acid concentration on yield of XOS showed a similar tendency. It was found that a maximum yield of XOS was achieved $\left(12.8 \mathrm{~g} \mathrm{XOS} / 100 \mathrm{~g}\right.$ RS) at $130{ }^{\circ} \mathrm{C}$ with $0.5 \% \mathrm{H}_{2} \mathrm{SO}_{4}$ for $2.0 \mathrm{~h}$ in this study. Recently, a relatively high XOS production from oil palm empty fruit bunch by hot compressed water pretreatment was studied [31]. Results showed that the highest XOS yield of 4.8/100 g biomass was obtained at $190{ }^{\circ} \mathrm{C}$ for $20 \mathrm{~min}$. As compared to hot compressed water treatment, the higher XOS yield was obtained by the dilute acid pretreatment under the optimized pretreatment condition in this study. Thus, dilute acid pretreatment is a promising method for the production of XOS from RS.

When XOS was produced by the dilute acid pretreatment, a variety of other compounds, such as formic acid, acetic acid, levulinic acid, lactic acid, hydroxymethylfurfural (HMF), and furfural was produced and appeared in the reaction media. The concentrations of the degraded byproducts of polysaccharides in the liquor phase are listed in Additional file 1: Table S1. It is interesting to note that the release of the degraded byproducts was closely related to the pretreatment conditions. For example, the concentrations of all the degraded byproducts increased with the growth of pretreatment temperature, $\mathrm{H}_{2} \mathrm{SO}_{4}$ concentration, or time. It was found that the maximum concentration of all the degraded byproducts was observed at $150{ }^{\circ} \mathrm{C}$ with $0.5 \% \mathrm{H}_{2} \mathrm{SO}_{4}$ for $2.0 \mathrm{~h}$. This indicated that the pretreatment temperature was more effective than the $\mathrm{H}_{2} \mathrm{SO}_{4}$ concentration and reaction time on the degraded byproducts from the polysaccharides. Due to the existence of the degraded byproducts from polysaccharides during the dilute acid pretreatment, the liquor phase was not a very pure source of XOS. In industry, to purify and then produce commercial XOS, the liquors have to be refined by removing non-XOS compounds [32]. In the past two decades, several promising purification technologies have been developed, such as membrane technology, chromatographic separation, solvent extraction, and adsorption [33-36]. Among these technologies, membrane separation technology is the most promising technology for refining and concentrating XOS as compared to others, since they may be less expensive [33]. In this case, the size-dependent selection mechanism of the membrane process results in the various concentrations of molecules with different molecular weights. Membrane separations have been applied for the preparation of several XOS from various biomasses, such as Olive stones, Pinus pinaster wood, and forest waste [37-39].

\section{Effects of dilute acid pretreatments on the yield, purity, molecular weight, and the structure feature of the alkali lignins released}

The yields of alkali lignins, which were calculated based on the lignins in respective substrate, are shown in Additional file 1: Table S2. The data showed that only $30.7 \%$ of the lignin from the control-S was obtained. For the pretreated substrates, the yields of the lignins increased with the raise of pretreatment temperature, $\mathrm{H}_{2} \mathrm{SO}_{4}$ concentration, or time. The increasing trend was related to the dilute acid pretreatment conditions, which cleaved the chemical bonds between lignin and hemicelluloses to different degrees [40]. Thus, the pretreatment accelerated more lignins release (33.16-47.76\%) during the alkali post-treatment. In other words, the dilute acid pretreatment was a promising process for efficiently loosing the tight cell wall structure, and then facilitating the release of lignin from the plant cell wall with the assist of alkali treatment. Moreover, to verify the purity of the lignins isolated, the associated polysaccharides in the lignins were detected by HPAEC (Additional file 1: Table S2). The date showed that all the lignins contained rather low amounts of associated polysaccharides $(<3.29 \%)$. As compared to the control lignin, the amounts of polysaccharides in the pretreated lignins were reduced, suggesting that the hemicelluloses were significantly degraded during the pretreatment under the conditions given. To assess the effect of the pretreatment on the molecular 
weight of the lignins isolated, the lignins were performed by GPC. The changes in molecular weight of the lignins based on the different pretreatment conditions are listed in Additional file 1: Table S3. The molecular weight $\left(M_{\mathrm{w}}\right)$ of control lignin was $2910 \mathrm{~g} \mathrm{~mol}^{-1}$, and its polydispersity $\left(M_{\mathrm{w}} / M_{\mathrm{n}}\right)$ was 1.87 . During the pretreatment, it was observed that the $M_{\mathrm{w}}\left(2320-2870 \mathrm{~g} \mathrm{~mol}^{-1}\right)$ of the lignins reduced slightly. This suggested that the lignins underwent a slight depolymerization under the conditions given [41]. In addition, the polydispersity indexes (1.451.78) of the alkali lignins were reduced slightly, implying the formation of some homogeneous lignin fragments, which were probably originated from successive dilute acid and alkali treatments.

To further reveal the structural transformations of the lignins isolated during the various pretreatment conditions, the samples were investigated by 2D-HSQC NMR spectra (Figs. 3, 4) and the signals are assigned (Additional file 1: Table S4) [42-47]. The inter-unit linkages in the lignins, $\beta$-ether $(\mathrm{A}, \beta-O-4)$ and phenylcoumaran $(\mathrm{B}$, $\beta-5)$ are identified due to the presence of cross-peaks at $\delta_{\mathrm{C}} / \delta_{\mathrm{H}} 71.7 / 4.83\left(\mathrm{~A}_{\alpha}\right), 59.7 / 3.54\left(\mathrm{~A}_{\gamma}\right)$, and 62.7/3.55 $\left(\mathrm{B}_{\gamma}\right)$, respectively. The cross-peaks of methoxy groups in the lignins $\left(-\mathrm{OCH}_{3}, \delta_{\mathrm{C}} / \delta_{\mathrm{H}} 55.6 / 3.72\right)$ were clearly observed. The aromatic lignin units syringyl (S), guaiacyl $(\mathrm{G})$, and $p$-hydroxyphenyl $(\mathrm{H})$ units showed prominent correlations at $\delta_{\mathrm{C}} / \delta_{\mathrm{H}} 103.8 / 6.70\left(\mathrm{~S}_{2,6}\right), 110.7 / 6.95\left(\mathrm{G}_{2}\right), 115.3 / 6.76$
$\left(\mathrm{G}_{5}\right), 118.9 / 6.76\left(\mathrm{G}_{6}\right)$, and $127.9 / 7.20\left(\mathrm{H}_{2,6}\right)$, respectively. Minor amounts of oxidized $\mathrm{S}$ units $\left(\mathrm{S}^{\prime}\right)$ were detected due to the presence of a correlation at $\delta_{\mathrm{C}} / \delta_{\mathrm{H}} 106.0 / 7.30\left(\mathrm{~S}_{2,6}^{\prime}\right)$. Moreover, the lignins obtained appeared to contain small amounts of $p$-hydroxycinnamates ( $p$-coumaric and ferulic acids). The $p$-coumaric acid (PCA) was characterized by some relatively intense correlations at $\delta_{\mathrm{C}} / \delta_{\mathrm{H}} 129.7 / 7.50$ $\left(\mathrm{PCA}_{2,6}\right)$ and $143.9 / 7.48\left(\mathrm{PCA}_{7}\right)$, while ferulic acid (FA) was found at $\delta_{\mathrm{C}} / \delta_{\mathrm{H}} 110.9 / 7.27\left(\mathrm{FA}_{2}\right), 116.6 .0 / 6.39\left(\mathrm{FA}_{8}\right)$, and 143.9/7.48 $\left(\mathrm{FA}_{7}\right)$. As can be seen, as the pretreatment temperature, $\mathrm{H}_{2} \mathrm{SO}_{4}$ concentration, or time increased, some changes appeared in the HSQC spectra of lignins. For example, the correlated signals of $\beta-O-4$ were diminished, and the correlated signals of PCA and FA were reduced simultaneously. Interestingly, the signal intensities of $\mathrm{C}_{2}-\mathrm{H}_{2}$ and $\mathrm{C}_{6}-\mathrm{H}_{6}$ in $\mathrm{G}$ unit were decreased gradually and disappeared under the harsh conditions, which is attributable to the fact that the condensation reaction probably occurred at $\mathrm{C}-2$ and $\mathrm{C}-6$ of $\mathrm{G}$ unit in lignin with the side chains of other lignin $[48,49]$.

In order to further investigate the effects of pretreatment conditions on the major hydroxyl groups of lignins, the lignins isolated were estimated by ${ }^{31} \mathrm{P}$ NMR based on the integration area of individual peaks (Additional file 1: Figure S4). The contents of aliphatic hydroxyls, condensed and non-condensed syringyl and guaiacyl hydroxyls, $p$-hydroxybenzoate phenolic hydroxyls, and

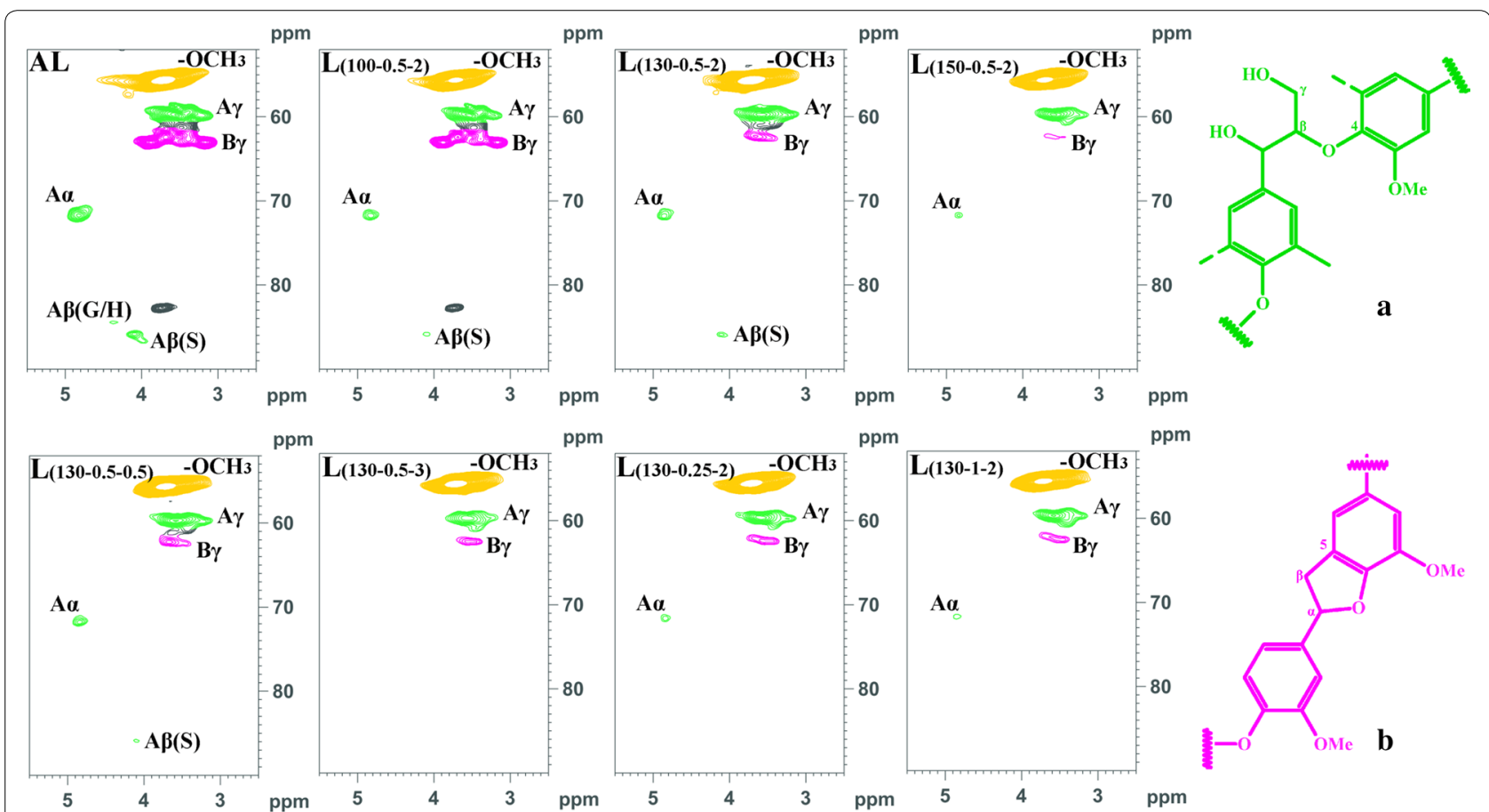

Fig. $32 \mathrm{D}-\mathrm{HSQC}$ spectra and the main structures of the lignins obtained from the integrated process under various processing conditions (sidechain region). $\beta$-aryl-ether units (a $\beta$-O-4) and phenylcoumaran substructures (b $\beta$-5) 


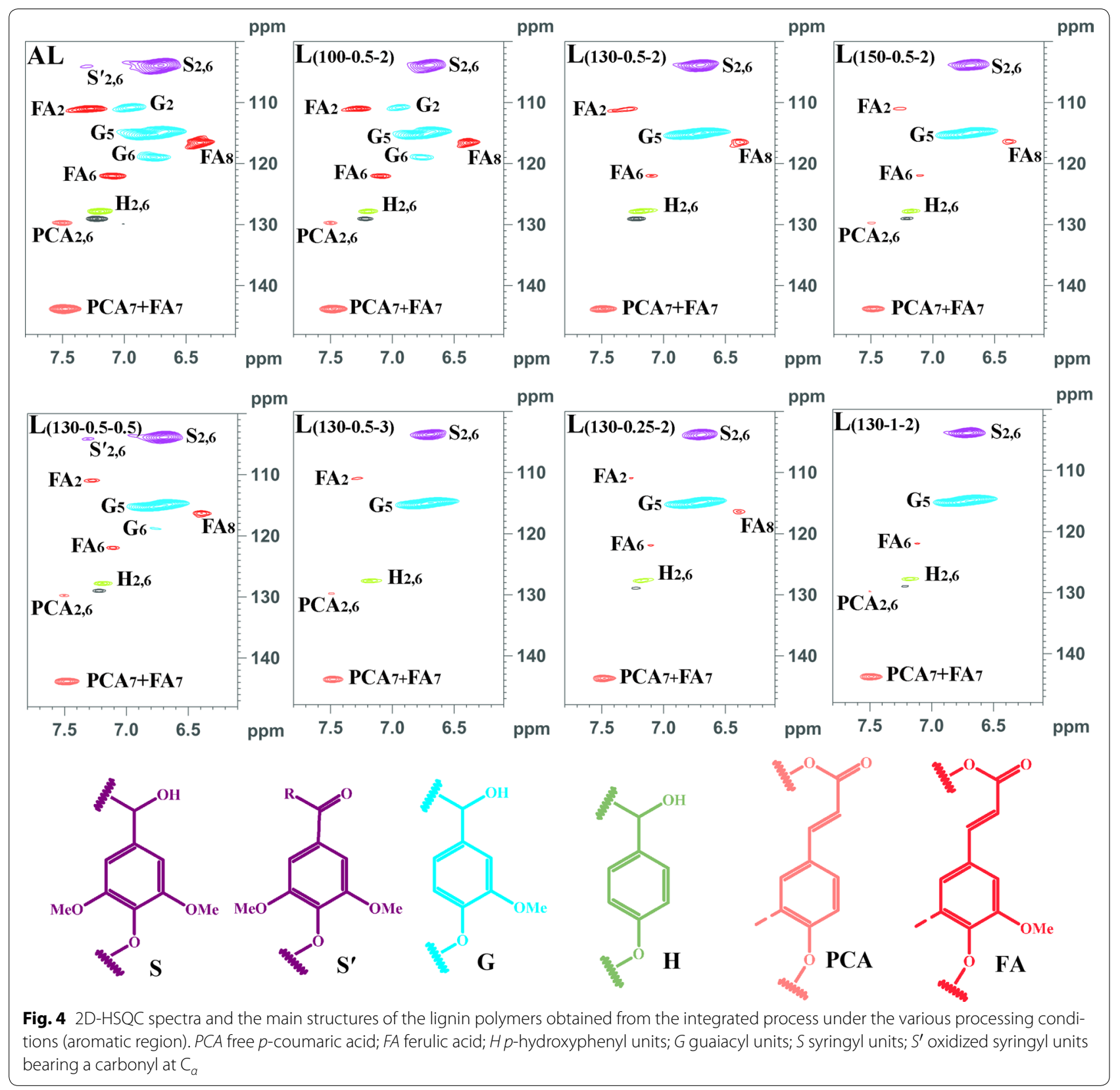

carboxylic acid hydroxyls were compared in different lignin fractions (Table 4) [50,51]. The results showed that the increase of the pretreatment temperature, $\mathrm{H}_{2} \mathrm{SO}_{4}$ concentration, or time resulted in the decrease of the aliphatic $\mathrm{OH}$ groups. This indicated that the hydroxyl groups in the side chain of lignin were probably fragmented and eliminated under the harsh conditions [52]. On the contrary, the phenolic $\mathrm{OH}$ groups in syringyl, guaiacyl, $p$-hydroxyphenyl $\mathrm{OH}$, and free $p$-coumaric acid units increased obviously. The increased phenolic $\mathrm{OH}$ groups were probably due to the cleavage of $\beta-O-4$ linkages under harsh conditions [53]. Similar observation has been reported in an autohydrolysis pretreatment of poplar [54]. It was noticed that harsh pretreatment conditions resulted in the slight increase of carboxyl groups, indicating that oxidation reaction occurred during the pretreatment. In this study, due to the cleavage of $\beta-O-4$ linkages during the synergetic treatment process, the lignin fractions with an increased phenolic $\mathrm{OH}$ groups had a potential application as biomaterials or biochemicals for industries such as lignin-phenol-formaldehyde resins and potential antioxidant [15, 55-59]. Ibrahim 
Table 4 Quantification of the functional groups $(\mathrm{mmol} / \mathrm{g})$ by quantitative ${ }^{31} \mathrm{P}-\mathrm{NMR}$ in the alkali lignins obtained by the integrated process

\begin{tabular}{|c|c|c|c|c|c|c|c|c|}
\hline \multirow[t]{2}{*}{ Lignin fractions } & \multirow[t]{2}{*}{ Aliphatic $\mathrm{OH}$} & \multicolumn{2}{|c|}{ Syringyl OH } & \multicolumn{2}{|c|}{ Guaiacyl OH } & \multirow[t]{2}{*}{$\mathrm{H}+\mathrm{P}-\mathrm{OH}$} & \multirow[t]{2}{*}{ Carboxylic group } & \multirow[t]{2}{*}{ Total phenolic $\mathrm{OH}$} \\
\hline & & $\mathrm{C}$ & NC & $\mathrm{C}$ & $\mathrm{NC}$ & & & \\
\hline $\mathrm{AL}$ & 2.72 & 0.02 & 0.12 & 0.07 & 0.35 & 0.16 & 0.86 & 0.72 \\
\hline$L_{(100-0.5-2)}$ & 1.56 & 0.11 & 0.34 & 0.20 & 0.59 & 0.31 & 0.93 & 1.55 \\
\hline $\mathrm{L}_{(130-0.5-2)}$ & 1.40 & 0.16 & 0.34 & 0.21 & 0.60 & 0.35 & 0.93 & 1.66 \\
\hline$L_{(150-0.5-2)}$ & 1.39 & 0.17 & 0.35 & 0.22 & 0.60 & 0.37 & 1.01 & 1.71 \\
\hline $\mathrm{L}_{(130-0.5-0.5)}$ & 1.45 & 0.11 & 0.31 & 0.19 & 0.57 & 0.34 & 0.93 & 1.52 \\
\hline$L_{(130-0.5-3)}$ & 1.39 & 0.19 & 0.36 & 0.22 & 0.62 & 0.37 & 0.97 & 1.76 \\
\hline $\mathrm{L}_{(130-0.25-2)}$ & 1.47 & 0.18 & 0.32 & 0.19 & 0.60 & 0.32 & 0.88 & 1.61 \\
\hline $\mathrm{L}_{(130-1-2)}$ & 1.37 & 0.20 & 0.37 & 0.26 & 0.68 & 0.42 & 1.06 & 1.93 \\
\hline
\end{tabular}

$\mathrm{C}$ condensed; $\mathrm{NC}$ non-condensed; $\mathrm{H}+\mathrm{P}-\mathrm{OH}$ the total content of $p$-hydroxyphenyl $\mathrm{OH}$ and free $p$-coumaric acid

et al. [56] examined the influence of chemical properties of lignins as well as determine their suitability for partial incorporation into phenol formaldehyde resins. The results showed that higher content of phenolic hydroxyl groups in kraft lignin allowed the activation of free ring position which makes the kraft lignin more reactive toward formaldehyde than the soda lignin. In addition, lignins have phenolic hydroxyl group that can act as a potential antioxidant in the food industry, preventing the loss of food flavor, color, and active vitamin content [57-59]. Pan et al. [59] reported that the content of phenolic hydroxyl groups in lignin was positively correlated to antioxidant activities of lignin.

\section{Effects of successive dilute acid and alkali treatments} on the enzymatic hydrolysis of cellulose in the substrates The performance of the enzymatic hydrolysis was assessed by determining glucose yield from the conversion of cellulose and this was expressed as the percentage of glucose released in relation to the total content of potential glucose in the starting material (i.e., the control, pretreated, and the post-treated substrates). Figure 5 shows the glucose yield of the control, pretreated (Fig. 5a), and post-treated substrates (Fig. 5b). As shown in Fig. 5a, the pretreatment on the glucose yield of the substrates increased by $37.4-71.2 \%$ as compared with control substrate (12.5\%). A possible reason was that the pretreatment resulted in increased enzyme accessibility due to significant removal of hemicelluloses as well as damage of surface morphology of the substrates. The glucose yield of the alkalitreated substrate without dilute acid pretreatment was only $35.6 \%$, while the glucose yield of the pretreated and post-treated substrates increased to $61.8-92.7 \%$. Thus, the combining of dilute acid and alkali treatments was highly effective for removing hemicelluloses and lignin from RS, resulting in increased enzymatic accessibility of the substrate and more efficient enzymatic hydrolysis. However, in the present study, there were no direct correlations between glucose yields and the residual contents of lignin or hemicelluloses in the pretreated and post-treated substrates. Meanwhile, it was found that crystallinity was not an important factor for the enzymatic hydrolysis of the substrates. The results indicated that there was no clear relationship between the $\mathrm{CrI}$ and glucose yield since the cellulose hydrolysis was not only affected by cellulose crystallinity but also by several other factors, such as contents and distribution of lignins or hemicelluloses, particle size, and porosity of the substrates. Thus, single factor may not adequately elaborate the differences of hydrolysis, and several factors impacted the cellulose hydrolysis of the substrates in the current study.

\section{Effects of successive dilute acid and alkali treatments on the higher value application of rice straw}

The maximum yield of XOS ( $12.8 \mathrm{~g}$ XOS/100 g RS) was obtained with a relatively low level of byproducts under the conditions of $130{ }^{\circ} \mathrm{C}$ with $0.5 \% \mathrm{H}_{2} \mathrm{SO}_{4}$ for $2.0 \mathrm{~h}$. Enhancement of the pretreatment time, temperature, or $\mathrm{H}_{2} \mathrm{SO}_{4}$ concentration reduced the yield of XOS and increased the concentrations of the byproducts. Based on the above process condition, during the further alkali post-treatment, a relatively high yield of lignin $(45.58 \%)$ and cellulose-rich substrate $(82.29 \%$ cellulose) were collected. For the cellulose-rich substrate, the glucose yield reached to $88.4 \%$ after enzymatic hydrolysis for $72 \mathrm{~h}$. Process yield was normalized to a common basis of $100 \mathrm{~g}$ of dried RS as the starting material (Fig. 6). By the biorefinery process, hemicelluloses, lignins, and cellulose of RS were effectively separated and utilized. Specifically, $12.8 \mathrm{~g}$ XOS was obtained, meanwhile, $14.2 \mathrm{~g}$ lignin and $30.3 \mathrm{~g}$ glucose were also collected. Zhu et al. [60] reported that the integration of autohydrolysis and 


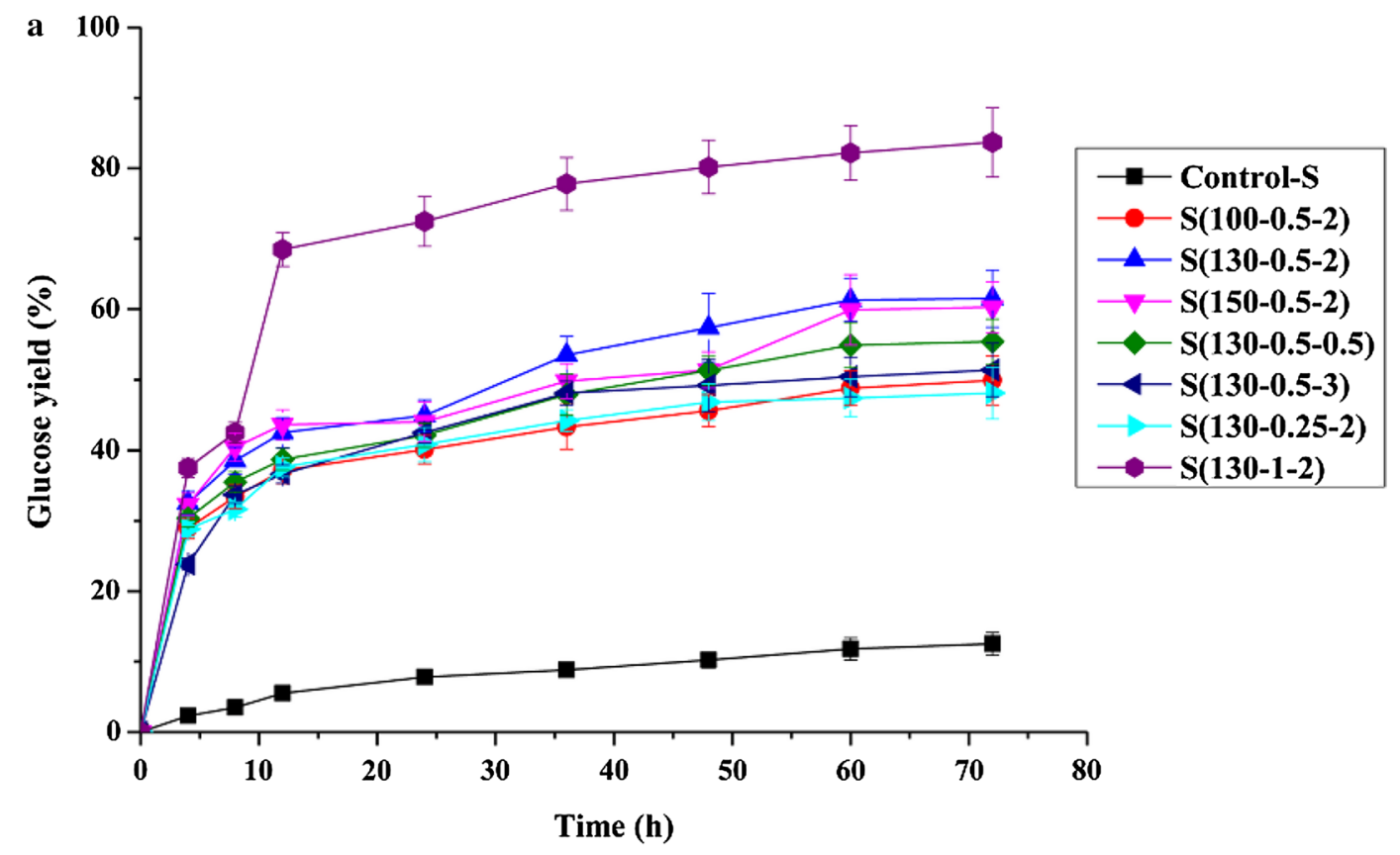

b

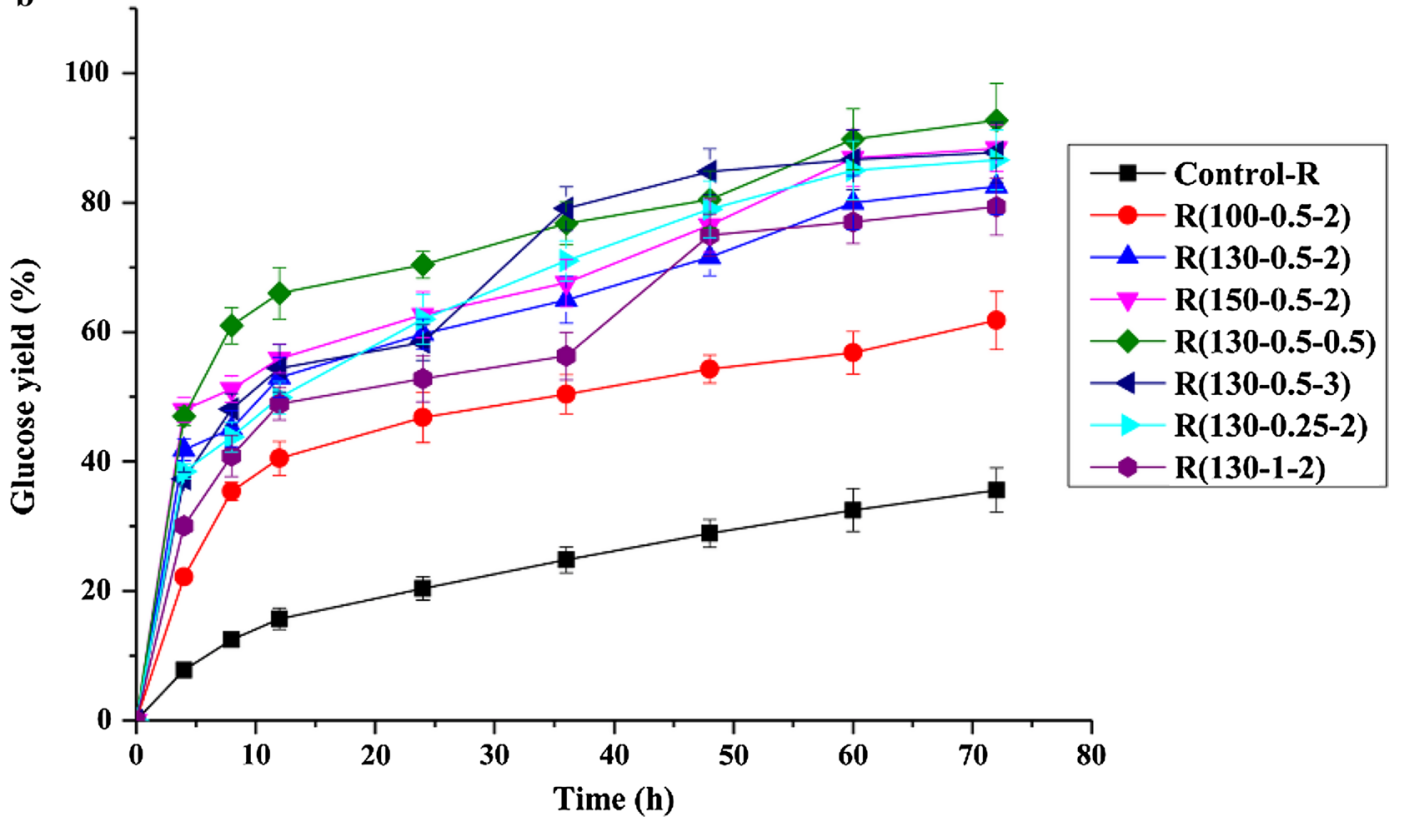

Fig. 5 Glucose yields of enzymatic hydrolysis of the control, pretreated (a), and post-treated substrates (b). Control-S extractive-free raw material, $S$ substrates obtained by the direct dilute acid pretreated materials under different conditions, Control-R substrate obtained by the alkali treatment raw material without dilute acid pretreatment, $R$ substrates obtained by the alkali post-treated substrates from the dilute acid pretreated substrates

organosolv pretreatment led to an enhanced digestibility of Eucommia ulmoides Oliver wood as compared to autohydrolysis or organosolv pretreatment alone. Under the condition of autohydrolysis at $180{ }^{\circ} \mathrm{C}$ for $0.5 \mathrm{~h}$ and sequent treatment using $50 \%$ aqueous ethanol with $1 \%$
$\mathrm{HCl}$ as a catalyst, $9.5 \mathrm{~g} \mathrm{XOS}, 14.5 \mathrm{~g}$ lignin, and $27.1 \mathrm{~g}$ glucose based on $100 \mathrm{~g}$ of initial biomass were obtained. Therefore, the biorefinery process based on successive dilute acid and alkali treatments for higher value application of rice straw is promising in industry. 


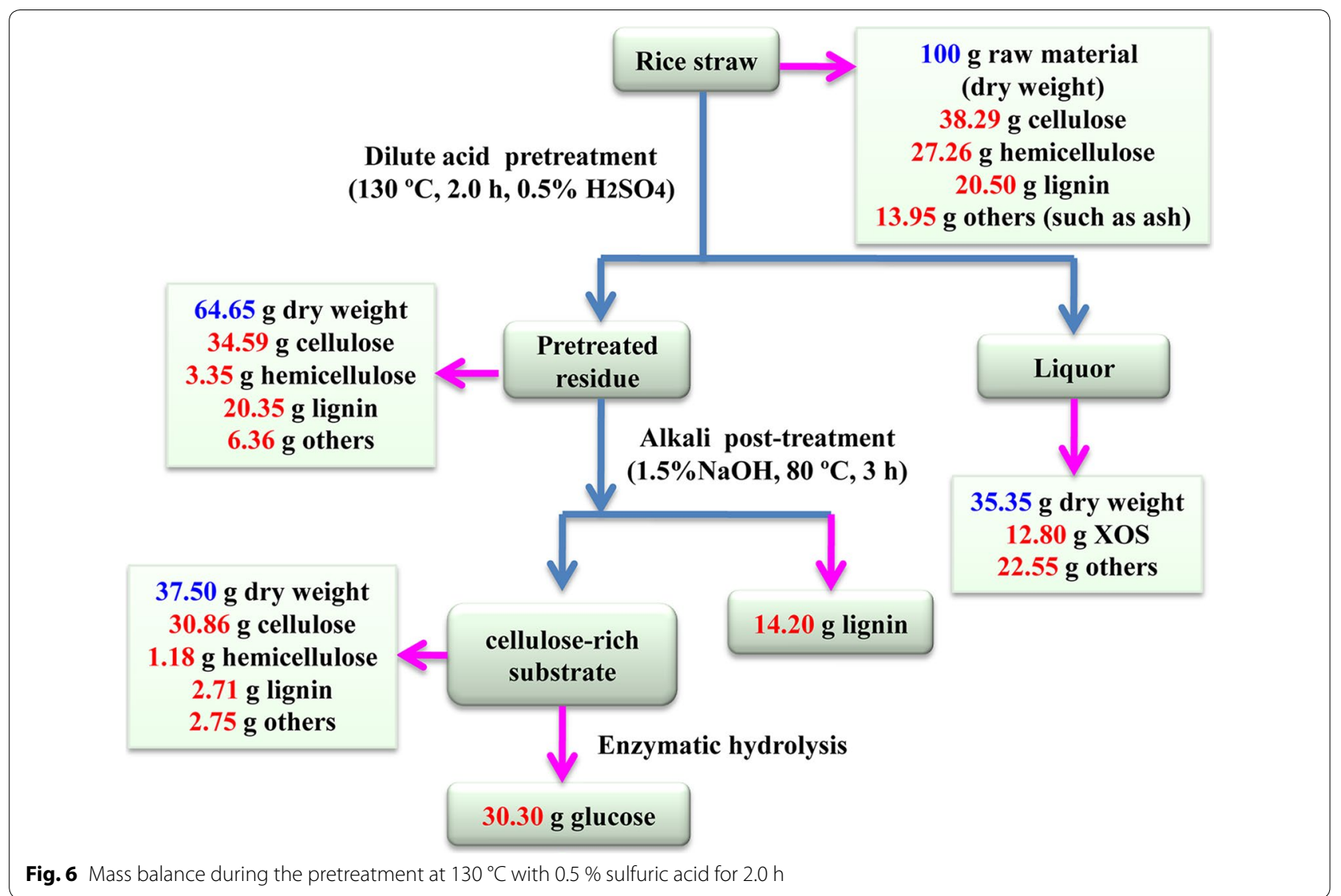

\section{Conclusions}

Successive treatments with dilute acid and alkali have been performed for the production of XOS, lignin, and cellulose-rich substrates for bioethanol production from rice straw. During the dilute acid pretreatment, a maximum production of XOS (12.8 g XOS/100 g RS) with a relatively low level of byproducts was obtained at $130{ }^{\circ} \mathrm{C}$ with $0.5 \% \mathrm{H}_{2} \mathrm{SO}_{4}$ for $2.0 \mathrm{~h}$. On further alkali treatment, $14.2 \mathrm{~g}$ lignin with a higher purity of $99.2 \%$ and $30.3 \mathrm{~g}$ glucose by enzymatic hydrolysis were also obtained from the successively treated substrates per $100 \mathrm{~g}$ starting material. The cleavage of $\beta-O-4$ linkages of lignin resulted in an increase of the content of phenolic $\mathrm{OH}$ groups with the elevating severity. During the treatment processes, the C- 2 and C- 6 of guaiacyl were condensed with the side chains of other lignin. The successive treatments of rice straw for production of XOS, lignin, and glucose can be further extended to the value-added application of various lignocellulosic biomasses.

\section{Methods}

\section{Raw materials}

RS was obtained from Shandong Province of China. RS was firstly dried in an oven at $60{ }^{\circ} \mathrm{C}$ for $24 \mathrm{~h}$ and then ground in a mill to obtain a $40-60$ mesh powder. Then, the powder was extracted with toluene-ethanol $(2: 1, \mathrm{v} / \mathrm{v})$ in a Soxhlet apparatus for $6 \mathrm{~h}$ to remove extractives and then dried in an oven at $60{ }^{\circ} \mathrm{C}$ for $24 \mathrm{~h}$ to serve as control substrate (control-S). The chemical composition of control-S $(\%, \mathrm{w} / \mathrm{w})$ was determined to be cellulose $38.29 \%$, hemicelluloses $27.46 \%$, and lignin $20.50 \%$, according to National Renewable Energy Laboratory's (NREL) standard analytical procedure. All chemicals were analytical grade and purchased from Sigma-Aldrich and Megazyme.

\section{Biorefinery process}

Control-S was successively treated by dilute acid and alkali. The dilute acid pretreatments $(100,110,120,130$, 140 , and $150{ }^{\circ} \mathrm{C}$ with $0.5 \% \mathrm{H}_{2} \mathrm{SO}_{4}$ for $1.0 \mathrm{~h} ; 130{ }^{\circ} \mathrm{C}$ with $0.5 \% \mathrm{H}_{2} \mathrm{SO}_{4}$ for $0.5,1.0,1.5,2.5$, and $3.0 \mathrm{~h}$; and $130{ }^{\circ} \mathrm{C}$ with $0.25,0.6,0.7,0.8$, and $1.0 \% \mathrm{H}_{2} \mathrm{SO}_{4}$ for $2.0 \mathrm{~h}$, respectively) were performed in a batch reactor $(100 \mathrm{~mL}$ internal volume, Sen Long Instruments Company, Beijing, China) at a solid-to-liquor ratio of $1: 15(\mathrm{~g} / \mathrm{mL})$. The reactor was made of Hastelloy C-276 to mitigate the effects of acid corrosion at high temperatures. The substrates pretreated with dilute acid were filtered off with a 
Buchner funnel, washed thoroughly with distilled water, and further dried in a cabinet oven with air circulation at $60{ }^{\circ} \mathrm{C}$ for $16 \mathrm{~h}$ and then labeled as $\mathrm{S}_{(100-0.5-2)}, \mathrm{S}_{(110-0.5-}$ 2), $S_{(120-0.5-2)}, S_{(130-0.5-2)}, S_{(140-0.5-2)}, S_{(150-0.5-2)}, S_{(130-0.5-0.5)}$, $S_{(130-0.5-1)}, S_{(130-0.5-1.5)}, S_{(130-0.5-2.5)}, S_{(130-0.5-3)}, S_{(130-0.25-2)}$, $\mathrm{S}_{(130-0.6-2)}, \mathrm{S}_{(130-0.7-2)}, \mathrm{S}_{(130-0.8-2)}$, and $\mathrm{S}_{(130-1-2)}$, respectively, corresponding to temperature, $\mathrm{H}_{2} \mathrm{SO}_{4}$ concentration, and time of pretreatment.

A further treatment was performed with $1.5 \%$ aqueous $\mathrm{NaOH}$ at $80^{\circ} \mathrm{C}$ for $3 \mathrm{~h}$ under a solid-to-liquid ratio of $1: 10(\mathrm{~g} / \mathrm{mL})$ to isolate lignin from the pretreated substrates and obtain post-treated substrates (cellulose-rich substrates). The collected liquid fractions were concentrated to $40 \mathrm{~mL}$ and poured into $200 \mathrm{~mL}$ of acidic water $(\mathrm{pH} 2.0$, adjusted by $\mathrm{HCl}$ ) to precipitate the alkali-soluble lignins. The precipitations were centrifuged, freeze-dried, and then named as $\mathrm{L}_{(100-0.5-2)}, \mathrm{L}_{(110-0.5-2)}, \mathrm{L}_{(120-0.5-2)}, \mathrm{L}_{(130-}$ $0.5-2), \mathrm{L}_{(140-0.5-2)}, \mathrm{L}_{(150-0.5-2)}, \mathrm{L}_{(130-0.5-0.5)}, \mathrm{L}_{(130-0.5-1)}, \mathrm{L}_{(130-0.5-}$ 1.5), $\mathrm{L}_{(130-0.5-2.5)}, \mathrm{L}_{(130-0.5-3)}, \mathrm{L}_{(130-0.25-2)}, \mathrm{L}_{(130-0.6-2)}, \mathrm{L}_{(130-0.7-2)}$, $\mathrm{L}_{(130-0.8-2)}$, and $\mathrm{L}_{(130-1-2)}$ according to the pretreatment conditions of the temperature, the $\mathrm{H}_{2} \mathrm{SO}_{4}$ concentration, and the time. Control lignin (i.e., alkaline lignin, $\mathrm{AL}$ ) was also isolated from the control-S under the same alkali treatment condition. Meanwhile, the alkaline post-treated substrates obtained from the corresponding pretreated substrates were filtered off with a Buchner funnel, washed thoroughly with distilled water, and further dried in a cabinet oven with air circulation at $60{ }^{\circ} \mathrm{C}$ for $16 \mathrm{~h}$ and then labeled as $\mathrm{R}_{(100-0.5-2)}, \mathrm{R}_{(110-0.5-2)}, \mathrm{R}_{(120-0.5-2)}, \mathrm{R}_{(130-0.5-2)}, \mathrm{R}_{(140-}$ 0.5-2), $\mathrm{R}_{(150-0.5-2)}, \mathrm{R}_{(130-0.5-0.5)}, \mathrm{R}_{(130-0.5-1)}, \mathrm{R}_{(130-0.5-1.5)}, \mathrm{R}_{(130-0.5-}$ 2.5), $\mathrm{R}_{(130-0.5-3)}, \mathrm{R}_{(130-0.25-2)}, \mathrm{R}_{(130-0.6-2)}, \mathrm{R}_{(130-0.7-2)}, \mathrm{R}_{(130-0.8-2) \text {, }}$ and $R_{(130-1-2)}$, respectively. As a control substrate, control$\mathrm{R}$ was also obtained from control-S under the same alkali treatment condition without dilute acid pretreatment. All of the prepared substrates (control, pretreated, and combining alkaline post-treated) were used to produce glucose by enzymatic hydrolysis in the present study.

\section{Enzymatic hrdrolysis}

Enzymatic hydrolysis was performed on the substrate $(2 \% \mathrm{w} / \mathrm{v})$ in $10 \mathrm{~mL} 50 \mathrm{mM}$ sodium acetate buffer $(\mathrm{pH}$ 4.8) with a $25 \mathrm{~mL}$ Erlenmeyer flask at $50{ }^{\circ} \mathrm{C}$ in a double-layer shaking incubators (ZWYR-2102C) (Shanghai, China) at $150 \mathrm{rpm}$ for $72 \mathrm{~h}$. Commercial enzyme (Cellic ${ }^{\circledR} \mathrm{CTec} 2,17 \mathrm{FPU} / \mathrm{g}$ substrate) was provided by Novozymes North America, Inc. (Franklinton, NC) and employed for all the enzymatic hydrolyses. The hydrolyzates were sampled periodically and analyzed by a HPAEC (Dionex, ICS 3000, U.S.) system equipped with an integral amperometric detector and CarboPac PA 100 $(4 \times 250 \mathrm{~mm}$, Dionex) analytical column. The detailed procedures were previously described in a publication [61]. All of the hydrolysis experiments were performed in triplicate, and average values and corresponding derivations were given.

\section{Analysis methods}

The chemical compositions (\%,w/w) of all the substrates were determined by NREL standard analytical procedure. The content of cellulose and hemicelluloses in the substrates was determined by HPAEC system on a CarboPac PA20 $(3 \times 150 \mathrm{~mm}$, Dionex $)$ analytical column. SEM images were performed with a S-3400 N II (Hitachi, Japan) instrument at $10 \mathrm{kV}$ and $81 \mathrm{~mA}$. FT-IR spectroscopic measurements were conducted on a Nicolet iN10 spectrophotometer in the range of $1760-860 \mathrm{~cm}^{-1}$ at $4 \mathrm{~cm}^{-1}$ resolution with 64 scans. XRD in reflection mode was performed using an XRD-6000 apparatus (Shimadzu, Japan) with Ni-filtered $\mathrm{Cu} \mathrm{K}$ radiation $(\chi=1.54 \AA)$ generated at $40 \mathrm{kV}$ and $30 \mathrm{~mA}$. The scattering angle $(2 \theta)$ was from 10 to $36^{\circ}$ at a scanning speed of $2 \% \mathrm{~min}$. The CrIs of the substrates were calculated from the ratio of the crystalline peak area to the total area of crystalline and amorphous peaks.

The liquor obtained from dilute acid pretreatment was stored and filtered to determine XOS and byproducts (e.g., formic acid, furfural). Liquor sample of $3 \mathrm{~mL}$ was post-hydrolyzed with $4 \% \mathrm{H}_{2} \mathrm{SO}_{4}$ at $121^{\circ} \mathrm{C}$ for $1 \mathrm{~h}$ to determine the total concentration of XOS. The increased concentrations of monosaccharides after post-hydrolysis were related to the concentration of XOS [62]. According to this procedure, saccharides of DP 2 or higher were considered as XOS. All the liquor fractions were filtered through $0.22-\mu \mathrm{m}$ filter and subsequently analyzed by HPAEC system. The amounts of byproducts in the liquid fractions were also quantitatively determined by high-performance liquid chromatography (HPLC; Agilent 1200, USA) with a Bio-Rad Aminex HPX-87H analytical column and a refractive index detector. The eluent was $5 \mathrm{mM} \mathrm{H}_{2} \mathrm{SO}_{4}$ solution with a volumetric flow rate of $0.5 \mathrm{~mL} / \mathrm{min}$. Column temperature was set at $50{ }^{\circ} \mathrm{C}$. The temperature of RI detector was $40^{\circ} \mathrm{C}$ and injection volume was $10 \mu \mathrm{L}$.

The associated polysaccharides in the lignins were calculated using HPAEC as reported previously [13]. Molecular weights of the lignins were determined by GPC with an ultraviolet detector at $240 \mathrm{~nm}$. The column used was a PL-gel $10 \mathrm{~mm}$ mixed-B $7.5 \mathrm{~mm}$ i.d. column, which was calibrated with PL polystyrene standards. Four milligrams of the lignins were dissolved in $2 \mathrm{~mL}$ of tetrahydrofuran (THF), and $20 \mu \mathrm{L}$ of lignin solutions was injected. The column was operated at ambient temperature and eluted with THF at a flow rate of $1.0 \mathrm{~mL} /$ min. The solution-state 2D HSQC spectra of the lignins were acquired on a Bruker AVIII $400 \mathrm{MHz}$ spectrometer at $25{ }^{\circ} \mathrm{C}$. The data were acquired using $60 \mathrm{mg}$ of lignin in $0.5 \mathrm{~mL}$ of DMSO- $d_{6}$. Functional groups (phenolic hydroxyl, aliphatic hydroxyl, and carboxyl groups) of the 


\section{lignins were determined by ${ }^{31} \mathrm{P}$ NMR spectra according to a previous publication [63].}

\section{Additional file}

Additional file 1: Table S1. The byproducts liberated during the dilute acid pretreatment. Table S2. Yield and contents of associated polysaccharides (absolute $\%, \mathrm{w} / \mathrm{w}$ ) of the lignins isolated with $1.5 \% \mathrm{NaOH}$ at $80^{\circ} \mathrm{C}$ for $2 \mathrm{~h}$ from the dilute acid pretreated rice straw. Table $\mathbf{S 3}$. Weight-average $\left(M_{w}\right)$ and number-average $\left(M_{n}\right)$ molecular weights, and polydispersity $\left(M_{w} / M_{n}\right)$ of the alkaline lignin fractions. Table S4. Assignments of ${ }^{13} \mathrm{C}-{ }^{1} \mathrm{H}$ cross-peaks in HSQC spectra of the alkaline lignins recovered from the integrated process. Figure S1. FT-IR spectra of the raw material, acid pretreated straw and alkali post-treated straw. Figure S2. SEM images of the raw material, acid pretreated straw and alkali post-treated straw. Figure S3. XRD patterns of the raw material, acid pretreated straw and alkali posttreated straw. Figure S4. ${ }^{31}$ P-NMR spectra of the lignins obtained from the integrated process under various processing conditions.

\section{Abbreviations}

XOS: xylooligosaccharides; RS: rice straw; HPAEC: high-performance anionexchange chromatography; SEM: scanning electron microscopy; FT-IR: fourier transform infrared; XRD: X-ray diffraction; NREL: National Renewable Energy Laboratory's; Crl: crystallinity index; HPLC: high-performance liquid chromatography; DP: degree of polymerization; GPC: gel permeation chromatography; THF: tetrahydrofuran; 2D-HSQC: two-dimensional heteronuclear single quantum coherence; HMF: hydroxymethylfurfural; $M_{w}$ : weight-average; $M_{n}$ : number-average; WSP: water-soluble polysaccharide; S: syringyl; $S^{\prime}$ : oxidized syringyl; G: guaiacyl; H: $p$-hydroxyphenyl; PCA: free $p$-coumaric acid; FA: ferulic acid.

\section{Authors' contributions}

SLS completed and performed the major experiments, analyzed the data, and prepared the manuscript. WJC, JNT, BW, XFC, and SNS helped with the overall pretreatment experiments of the pretreatment and the instrumental analysis. RCS designed the project, supervised the experiments, and finalized the manuscript. All authors read and approved the final manuscript.

\section{Acknowledgements}

The authors are extremely grateful to financial support from the Fundamental Research Funds for the Central Universities (BLYJ201520), National Science Foundation of China (31430092), International Science and Technology Program of China (2015DFG31860), and Fundamental Research Funds for the Central Universities (2015ZCQ-CL-02).

\section{Competing interests}

The authors declare that they have no competing interests.

\section{Availability of supporting data}

The authors promise the availability of supporting data.

\section{Consent for publication}

All authors have approved the manuscript to be published.

\section{Funding}

Funding sources have been addressed in the Acknowledgements.

Received: 11 August 2016 Accepted: 4 October 2016

Published online: 18 October 2016

\section{References}

1. Andreae MO, Merlet P. Emission of trace gases and aerosols from biomass burning. Glob Biogeochem Cycles. 2001;15:955-66.
2. Li X, Wang S, Duan L, Hao J, Li C, Chen Y, Yang L. Particulate and trace gas emissions from open burning of wheat straw and corn stover in China. Environ Sci Technol. 2007;41:6052-8.

3. Jahan MS, Shamsuzzaman M, Rahman MM, Moeiz SI, Ni Y. Effect of preextraction on soda-anthraquinone (AQ) pulping of rice straw. Ind Crops Prod. 2012;37:164-9.

4. Yang L, Cao J, Mao J, Jin Y. Sodium carbonate-sodium sulfite pretreatment for improving the enzymatic hydrolysis of rice straw. Ind Crops Prod. 2013;43:711-7.

5. PuY, Hu F, Huang F, Davison BH, Ragauskas AJ. Assessing the molecular structure basis for biomass recalcitrance during dilute acid and hydrothermal pretreatments. Biotechnol Biofuels. 2013;6:15.

6. Suwannarangsee S, Bunterngsook B, Arnthong J, Paemanee A, Thamchaipenet A, Eurwilaichitr L, Laosiripojana N, Champreda V. Optimisation of synergistic biomass-degrading enzyme systems for efficient rice straw hydrolysis using an experimental mixture design. Bioresour Technol. 2012;119:252-61.

7. Lim JS, Manan ZA, Alwi SRW, Hashim H. A review on utilisation of biomass from rice industry as a source of renewable energy. Renew Sust Energy Rev. 2012;16:3084-94.

8. Zheng G, Cui Y, Karabulut E, Wågberg L, Zhu H, Hu L. Nanostructured paper for flexible energy and electronic devices. MRS Bull. 2013;38:320-5.

9. Tilman D, Socolow R, Foley JA, Hill J, Larson E, Lynd L, Pacala S, Reilly J, Searchinger T, Somerville C. Beneficial biofuels - the food, energy, and environment trilemma. Science. 2009;325:270-1.

10. Park JH, Hong JY, Jang HC, Oh SG, Kim SH, Yoon JJ, Kim YJ. Use of Gelidium amansii as a promising resource for bioethanol: a practical approach for continuous dilute-acid hydrolysis and fermentation. Bioresour Technol. 2012:108:83-8.

11. Chen Y, Stevens MA, Zhu Y, Holmes J, Xu H. Understanding of alkaline pretreatment parameters for corn stover enzymatic saccharification. Biotechnol Biofuels. 2013;6:8.

12. Oliveira FM, Pinheiro IO, Souto-Maior AM, Martin C, Gonçalves AR, Rocha GJ. Industrial-scale steam explosion pretreatment of sugarcane straw for enzymatic hydrolysis of cellulose for production of second generation ethanol and value-added products. Bioresour Technol. 2013;130:168-73.

13. Sun SL, Wen JL, Sun SN, Sun RC. Systematic evaluation of the degraded products evolved from the hydrothermal pretreatment of sweet sorghum stems. Biotechnol Biofuels. 2015;8:37.

14. Zakzeski J, Bruijnincx PC, Jongerius AL, Weckhuysen BM. The catalytic valorization of lignin for the production of renewable chemicals. Chem Rev. 2010;110:3552-99.

15. El Mansouri N-E, Salvadó J. Structural characterization of technical lignins for the production of adhesives: application to lignosulfonate, kraft, sodaanthraquinone, organosolv and ethanol process lignins. Ind Crops Prod. 2006;24:8-16.

16. Sun R, Fang J, Tomkinson J, Bolton J. Physicochemical and structural characterization of alkali soluble lignins from oil palm trunk and empty fruit-bunch fibers. J Agric Food Chem. 1999;47:2930-6.

17. Zhang MJ, Wang F, Su RX, Qi W, He ZM. Ethanol production from high dry matter corncob using fed-batch simultaneous saccharification and fermentation after combined pretreatment. Bioresour Technol. 2010;101:4959-64.

18. Kim S, Park JM, Seo JW, Kim CH. Sequential acid-/alkali-pretreatment of empty palm fruit bunch fiber. Bioresour Technol. 2012;109:229-33.

19. Baadhe RR, Potumarthi R, Mekala NK. Influence of dilute acid and alkali pretreatment on reducing sugar production from corncobs by crude enzymatic method: a comparative study. Bioresour Technol. 2014;162:213-7.

20. Lee JW, Kim JY, Jang HM, Lee MW, Park JM. Sequential dilute acid and alkali pretreatment of corn stover: sugar recovery efficiency and structural characterization. Bioresour Technol. 2015;182:296-301.

21. Hsu TC, Guo GL, Chen WH, Hwang WS. Effect of dilute acid pretreatment of rice straw on structural properties and enzymatic hydrolysis. Bioresour Technol. 2010;101:4907-13.

22. Zhang QZ, Cai WM. Enzymatic hydrolysis of alkali-pretreated rice straw by Trichoderma reesei ZM4-F3. Biomass Bioenerg. 2008;32:1130-5.

23. Kim SB, Lee SJ, Lee JH, et al. Pretreatment of rice straw with combined process using dilute sulfuric acid and aqueous ammonia. Biotechnol Biofuels. 2013;6:1. 
24. Garrote G, Dominguez H, Parajo J. Study on the deacetylation of hemicelluloses during the hydrothermal processing of Eucalyptus wood. Holz Roh Werkst. 2001;59:53-9.

25. Kumar R, Hu F, Sannigrahi P, Jung S, Ragauskas AJ, Wyman CE. Carbohydrate derived-pseudo-lignin can retard cellulose biological conversion. Biotechnol Bioeng. 2013;110:737-53.

26. Wen JL, Xue BL, Xu F, Sun RC, Pinkert A. Unmasking the structural features and property of lignin from bamboo. Ind Crops Prod. 2013;42:332-43.

27. Xiao LP, Xu F, Sun RC. Chemical and structural characterization of lignins isolated from caragana sinica. Fiber Polym. 2011;12:316-23.

28. Sun SN, Cao XF, Sun SL, Xu F, Song XL, Sun RC, Jones GL. Improving the enzymatic hydrolysis of thermo-mechanical fiber from Eucalyptus urophylla by a combination of hydrothermal pretreatment and alkali fractionation. Biotechnol Biofuels. 2014;7:116.

29. Himmel ME, Ding SY, Johnson DK, Adney WS, Nimlos MR, Brady JW, Foust TD. Biomass recalcitrance: engineering plants and enzymes for biofuels production. Science. 2007;315:804-7.

30. Bi S, Peng L, Chen K, Zhu Z. Enhanced enzymatic saccharification of sugarcane bagasse pretreated by combining $\mathrm{O}_{2}$ and $\mathrm{NaOH}$. Bioresour Technol. 2016;214:692-9.

31. Zakaria MR, Hirata S, Fujimoto S, Hassan MA. Combined pretreatment with hot compressed water and wet disk milling opened up oil palm biomass structure resulting in enhanced enzymatic digestibility. Bioresour Technol. 2015;193:128-34.

32. Vázquez MJ, Garrote G, Alonso JL, Domínguez H, Parajó JC. Refining of autohydrolysis liquors for manufacturing xylooligosaccharides: evaluation of operational strategies. Bioresour Technol. 2005;96:889-96.

33. Pinelo M, Jonsson G, Meyer AS. Membrane technology for purification of enzymatically produced oligosaccharides: molecular and operational features affecting performance. Sep Purif Technol. 2009;70:1-11.

34. Chapla D, Pandit P, Shah A. Production of xylooligosaccharides from corncob xylan by fungal xylanase and their utilization by probiotics. Bioresour Technol. 2012;115:215-21.

35. Vegas R, Alonso JL, Domınguez H, Parajo JC. Processing of rice husk autohydrolysis liquors for obtaining food ingredients. J Agric Food Chem. 2004;52:7311-7.

36. Sanz ML, Polemis N, Morales V, Corzo N, Drakoularakou A, Gibson GR, Rastall RA. In vitro investigation into the potential prebiotic activity of honey oligosaccharides. J Agric Food Chem. 2005;53:2914-21.

37. dos Santos JLC, Fernandes MC, Lourenco PML, Duarte LC, Carvalheiro F, Crespo JG. Removal of inhibitory compounds from olive stone autohydrolysis liquors by nanofiltration. Desalin Water Treat. 2011;27:90-6.

38. González-Muñoz MJ, Rivas S, Santos V, Parajó JC. Fractionation of extracted hemicellulosic saccharides from Pinus pinaster wood by multistep membrane processing. J Membr Sci. 2013;428:281-9.

39. Ko CH, Shih TL, Jhan BT, Chang FC, Wang YN, Wang YC. Production of xylooligosaccharides from forest waste by membrane separation and Paenibacillus xylanase hydrolysis. BioResources. 2012;8:612-27.

40. Sun RC, Tomkinson J, Ma PL, Liang SF. Comparative study of hemicelluloses from rice straw by alkali and hydrogen peroxide treatments. Carbohyd Polym. 2000;42:111-22.

41. Zhang L, Yan L, Wang Z, Laskar DD, Swita MS, Cort JR, Yang B. Characterization of lignin derived from water-only and dilute acid flowthrough pretreatment of poplar wood at elevated temperatures. Biotechnol Biofuels. 2015;8:203.

42. Del Río JC, Rencoret J, Prinsen P, Martínez AT, Ralph J, Gutiérrez A. Structural characterization of wheat straw lignin as revealed by analytical pyrolysis, 2D-NMR, and reductive cleavage methods. J Agric Food Chem. 2012;60:5922-35.

43. Sun SL, Huang Y, Sun RC, Tu MB. The strong association of condensed phenolic moieties in isolated lignins with their inhibition of enzymatic hydrolysis. Green Chem. 2016;18:4276-86.

44. Ralph J, Lundquist K, Brunow G, Lu F, Kim H, Schatz PF, Marita JM, Hatfield RD, Ralph SA, Christensen JH. Lignins: natural polymers from oxidative coupling of 4-hydroxyphenyl-propanoids. Phytochem Rev. 2004;3:29-60.
45. Rico A, Rencoret J, del Río JC, Martínez AT, Gutiérrez A. Pretreatment with laccase and a phenolic mediator degrades lignin and enhances saccharification of Eucalyptus feedstock. Biotechnol Biofuels. 2014;7:6.

46. Trajano HL, Engle NL, Foston M, Ragauskas AJ, Tschaplinski TJ, Wyman CE. The fate of lignin during hydrothermal pretreatment. Biotechnol Biofuels. 2013;6:110.

47. Sasaki K, Okamoto M, Shirai T, Tsuge Y, Teramura H, Sasaki D, Kawaguchi $\mathrm{H}$, Hasunuma T, Ogino C, Matsuda F. Precipitate obtained following membrane separation of hydrothermally pretreated rice straw liquid revealed by 2D NMR to have high lignin content. Biotechnol Biofuels. 2015;8:88.

48. Shen XJ, Wang B, Huang PL, Wen JL, Sun RC. Effects of aluminum chloride-catalyzed hydrothermal pretreatment on the structural characteristics of lignin and enzymatic hydrolysis. Bioresour Technol. 2016;206:57-64.

49. Torr KM, Love KT, Çetinkol ÖP, Donaldson LA, George A, Holmes BM, Simmons BA. The impact of ionic liquid pretreatment on the chemistry and enzymatic digestibility of Pinus radiata compression wood. Green Chem. 2012;14:778-87.

50. Argyropoulos DS. Quantitative phosphorus-31 NMR analysis of lignins, a new tool for the lignin chemist. J Wood Chem Technol. 1994;14:45-63.

51. Pu YQ, Cao SL, Ragauskas AJ. Application of quantitative ${ }^{31} P$ NMR in biomass lignin and biofuel precursors characterization. Energy Environ Sci. 2011;4:3154-66

52. Wen JL, Yuan TQ, Sun SL, Xu F, Sun RC. Understanding the chemical transformations of lignin during ionic liquid pretreatment. Green Chem. 2014;16:181-90.

53. Brosse N, El Hage R, Chaouch M, Pétrissans M, Dumarçay S, Gérardin P. Investigation of the chemical modifications of beech wood lignin during heat treatment. Polym Degrad Stab. 2010;95:1721-6.

54. Samuel R, Cao S, Das BK, Hu F, Pu Y, Ragauskas AJ. Investigation of the fate of poplar lignin during autohydrolysis pretreatment to understand the biomass recalcitrance. RSC Adv. 2013;3:5305-9.

55. Hussin MH, Rahim AA, Ibrahim MNM, Brosse N. Physicochemical characterization of alkaline and ethanol organosolv lignins from oil palm (Elaeis guineensis) fronds as phenol substitutes for green material applications. Ind Crops Prod. 2013;49:23-32.

56. Ibrahim MNM, Zakaria N, Sipaut CS, Sulaiman O, Hashim R. Chemical and thermal properties of lignins from oil palm biomass as a substitute for phenol in a phenol formaldehyde resin production. Carbohyd Polym. 2011;86:112-9.

57. Dizhbite T, Telysheva G, Jurkjane V, Viesturs U. Characterization of the radical scavenging activity of lignins - natural antioxidants. Bioresour Technol. 2004;95:309-17.

58. Sun SL, Wen JL, Ma MG, Sun RC, Jones GL. Structural features and antioxidant activities of degraded lignins from steam exploded bamboo stem. Ind Crops Prod. 2014;56:128-36.

59. Pan XJ, Kadla JF, Ehara K, Gilkes N, Saddler JN. Organosolv ethanol lignin from hybrid poplar as a radical scavenger: relationship between lignin structure, extraction conditions, and antioxidant activity. J Agric Food Chem. 2006;54:5806-13.

60. Zhu MQ, Wen $J$, Su YQ, Wei Q, Sun RC. Effect of structural changes of lignin during the autohydrolysis and organosolv pretreatment on Eucommia ulmoides Oliver for an effective enzymatic hydrolysis. Bioresour Technol. 2015;185:378-85.

61. Sun SL, Sun SN, Wen JL, Zhang XM, Peng F, Sun RC. Assessment of integrated process based on hydrothermal and alkaline treatments for enzymatic saccharification of sweet sorghum stems. Bioresour Technol. 2015;175:473-9.

62. Gullón B, Yáñez R, Alonso J, Parajó J. Production of oligosaccharides and sugars from rye straw: a kinetic approach. Bioresour Technol. 2010;101:6676-84.

63. Granata A, Argyropoulos DS. 2-Chloro-4,4,5,5-tetramethyl-1,3,2dioxaphospholane, a reagent for the accurate determination of the uncondensed and condensed phenolic moieties in lignins. J Agric Food Chem. 1995;43:1538-44. 